\begin{tabular}{|c|ccc|c|}
\hline & PORT SAID ENGINEERING RESEARCH JOURNAL \\
\hline
\end{tabular}

\title{
Mechanical Properties of UHPC with Hybrid Fibers
}

\author{
R. M.kilany ${ }^{1}$, K. Sharobim ${ }^{2}, N-A . H u s s i e n^{3}$
}

\begin{abstract}
The effect of steel, and hybrid fiber contents are studied on the mechanical properties of the new generation Ultra High Performance Concrete (UHPC) produced by available local materials. According to the curing condition and fiber content; the compressive strength, flexural strength, and tensile strength reach $175 \mathrm{MPa}, 21.35 \mathrm{MPa}$, and $12.5 \mathrm{MPa}$ respectively. Based on the data of testing, an optimized concrete mix proportion compressive strength of more than 150 $\mathrm{MPa}$ is proposed.
\end{abstract}

\section{INTRODUCTION}

Advances in the knowledge and understanding of the behaviors of concrete on the microstructural level have led to the development of the next generation of concrete, namely Ultra-High Performance Concrete (UHPC). UHPC is a cementitious composite material composed of an optimized gradation of granular constituents with a low water-to-cementations materials ratio, and a high percentage of discontinuous internal fiber reinforcement. The mechanical properties of UHPC include compressive strength greater than $150 \mathrm{MPa}$ and tensile strength greater than $5 \mathrm{MPa}$. UHPC has a discontinuous pore structure that reduces liquid ingress, significantly enhancing durability as compared to conventional and high-strength concretes. With time new structural concepts will be developed that can better utilize the superb properties of high strength and durability of the UHPC. Recently, it is required to look for a material with four distinctive properties:

- Strength

- Workability

- Durability

- Affordability (cost).

The future of UHPC depends on both time and cost to push it into popular applications. To fully utilize the capacity of UHPC, new applications must be developed. The very high strength of UHPC will not be necessary if we keep using it on existing types of structures. New forms of structures have to be developed to benefit the advantages of the new material. It is required to think "outside the box" to find more appropriate applications. Therefore, being innovative is necessary .

Besides the ecological advantages, other economical benefits over normal concrete are:

- Fewer quantities of concrete to be placed

- Lower amount of reinforcement

- Smaller formwork area

\footnotetext{
Tivil Engineering Department, Faculty of Engineering, Port Said University, Port said, Egypt; E-mail: rasha a arhman@yahoo.com

${ }^{2}$ Prof. of Civil Engineering Department, Faculty of Engineering, Suez. Canal University, Ismailia, Egypt;

E-mail:k.sharobim@scuegypt.edu.eg

3 Civil Engineering Department, Faculty of Engineering, Port Said University, Port Said, Egypt.

E-mail: Nourallah@eng.psu.edu.eg.
}

- Less dead load; this means smaller foundations or more floors.

As a result, materials, wages, transport and handling costs are expected to be reduced.

Both the high compressive strength and the improved durability of UHPC are based on the following principles:

- A very low water-to-cement ratio of about 0.20 to 0.25 resulting in a very dense and strong structure of the hydrated products and minimizing the capillary pores.

- A high packing density especially of the fine grains in the binder matrix reduces the water demand of the fresh mix and increases the compressive strength as well as the brittleness of the concrete.

- The use of higher amounts of effective superplasticizers to adjust the workability.

- Using steel or other fiber reinforcements to increase the tensile, the flexural and the shear strengths and to make the concrete sufficiently ductile.

The steel fiber reinforcement included in UHPC provides a number of advantages, most notably in terms of tensile behaviour. The presence of steel fibers is used to bridge the micro cracks, as discussed by shah [1], and can increase the tensile strength. Normally, a compression test on high-performance concrete would result in a very brittle, dramatic failure.

This agreed with Orgass and Klung [2] that stated that a ductile failure was observed till fiber volume of $2 \%$ by volume. The addition of $1.5 \%$ by volu me of steel fibers can increase the direct tensile strength by up to $40 \%$ and the flexural strength by up to $150 \%$ in conventional concrete. Steel fibers do not affect free shrinkage. Steel fibers delay the fracture of restrained concrete during shrinkage and improve stress relaxation by creep mechanis ms [3, 4]. Babu and Kumar [5] investigated the effect of adding glass fibers and concluded that there is increase in the compressive strength up to $1 \%$ by volume at higher fiber percentages and the strength decrease if the fiber content is increased significantly. Barros and Figueiras [6] investigated the tensile behaviour of glass fiber reinforced concrete specimens at 28 days of age. It was observed that fracture energy of cement based 
materials is significantly increased by adding glass fiber to the mix composition. Due to the very low water-tocementitious material ratio in UHPC, the full hydration potentials of the cement and silica fume are never reached. However, improved performance has been observed after thermally treating UHPC using combinations of heat, steam, and pressure treatments [7, 8, and 9]. The thermal treatment appears to allow continued hydration of the Portland cement and pozzolanic reaction of the silica fume [10]. The thermal treatment also has a strong influence on the properties of hardened concrete; proper curing will increase durability, strength, abrasion resistance, volume stability, and resistance to freezing and thawing and deicers. Graybeal [9] observed improved durability characteristics including increased resistance to chloride penetration and abrasion. These findings indicate that the full promises of UHPC's benefits are not only realized because of particle packing, but also due to the method of curing.

\section{EXPERMINTAL PROGRAM}

The purpose of this research is to investigate the effect of:

1. Diffe rent curing conditions.

2. Steel fiber content.

3. Hybrid fiber (glass \& steel).

\section{$2.1 \quad$ Material}

Based on the principle of ultra high performance concrete, the materials used in this study are shown in Table 1. The aggregate used is brought from Suez area. Sand used in this study was passed through a No.30 sieve to obtain the desired particle sizes. The aggregates were washed and oven dried to achieve $0 \%$ moisture content. The grading of aggregate used is shown in Table 2. The cement used was Sinai Portland Cement (grade $52.2 \mathrm{~N}$ ). Silica fume was added to the mixture with a dosage $25 \%$ of the cement weight. The superplasticizer known commercially by Basf Gleniu m C315 was used to increase the workability of concrete mix. Steel fiber used has a diameter of $0.2 \mathrm{~mm}$ and with a length of $12.7 \mathrm{~mm}$, i.e. the aspect ratio is 64 . The glass fibers used in this test program have a nominal diameter of $0.15 \mathrm{~mm}$ and a nominal length of $12.0 \mathrm{~mm}$.

Table 1. Material Properties

\begin{tabular}{|c|c|}
\hline Material & Characterizes \\
\hline cement & $\begin{array}{c}\text { Compressive strength at } 28 \text { days } \\
=55 \mathrm{MPa}\end{array}$ \\
& $\begin{array}{c}\text { Comply with the Egyptian standard } \\
\text { specifications }\end{array}$ \\
\hline $\begin{array}{c}\text { Additive } \\
\text { (silica fume) }\end{array}$ & $\begin{array}{c}\text { Specific surface area } \\
=15.2 \times 10^{4} \mathrm{c} \mathrm{m}^{2} / \mathrm{g} \mathrm{m} \\
\text { Specific gravity }=2.15\end{array}$ \\
\hline Fine & Bulk density $=1.763 \mathrm{t} / \mathrm{m}^{3}$ \\
Aggregate & F.M. $=2.56$ \\
\hline Chemical & Specific gravity $=1.08$ \\
\hline
\end{tabular}

Admixture Comply with the requirements for superplasticizers according to EN 934-2, SIA 262 (2003)

Table 2. Sand Grading

\begin{tabular}{|c|c|c|c|c|}
\hline Sieve Size $(\mathrm{mm})$ & 1.18 & 0.6 & 0.3 & 0.15 \\
\hline$\%$ passing & 100 & 100 & 50 & 10 \\
\hline
\end{tabular}

\subsection{Mix Proportion}

Mix proportions were tested to study the effective parameters. These mix proportions are shown in Tables 3, 4 and 5, where:

M: Control mix.

P: Mixes with steel fiber.

R: Mixes with hybrid fiber (glass: steel; 1:1).

A: Mixes with hybrid fiber (glass: steel; 1:2).

Table 3: Mix Proportions for Cubic Meter Mix with Steel Fibers $(\mathrm{Kg})$

\begin{tabular}{|c|c|c|c|c|}
\hline Index & $\mathrm{M}$ & $\mathrm{P}_{1}$ & $\mathrm{P}_{2}$ & $\mathrm{P}_{3}$ \\
\hline Cement & 950 & 950 & 950 & 950 \\
\hline Silica & 237.5 & 237.5 & 237.5 & 237.5 \\
\hline Sand & 950 & 950 & 950 & 950 \\
\hline Water & 190 & 190 & 190 & 190 \\
\hline Superplasticizer & $2 \%$ & $2 \%$ & $2 \%$ & $2 \%$ \\
\hline W/C & 0.2 & 0.2 & 0.2 & 0.2 \\
\hline w/c.m & 0.16 & 0.16 & 0.16 & 0.16 \\
\hline Steel Fiber & 0 & 75 & 150 & 225 \\
$(0 \%)$ & $(1 \%)$ & $(2 \%)$ & $(3 \%)$ \\
\hline Glass Fiber & $(0 \%)$ & $0 \%$ & $0 \%$ & $0 \%$ \\
\hline
\end{tabular}

Where, w/c.m is water-to- (cement + silica fume) ratio

Table 4: Mix Proportions for Cubic Meter Mix with Hybrid (1:1) Fibers (Kg)

\begin{tabular}{|c|c|c|c|}
\hline Index & $\mathrm{R}_{1}$ & $\mathrm{R}_{2}$ & $\mathrm{R}_{3}$ \\
\hline Cement & 950 & 950 & 950 \\
\hline Silica & 237.5 & 237.5 & 237.5 \\
\hline Sand & 950 & 950 & 950 \\
\hline Water & 190 & 190 & 190 \\
\hline Superplasticizer & $2 \%$ & $2 \%$ & $2 \%$ \\
\hline W/C & 0.2 & 0.2 & 0.2 \\
\hline w/c.m & 0.16 & 0.16 & 0.16 \\
\hline Steel Fiber & 37.5 & 75 & 112.5 \\
$(0.5 \%)$ & $(1 \%)$ & $(1.5 \%)$ \\
\hline Glas F Fiber & $\begin{array}{c}12.5 \\
(0.5 \%)\end{array}$ & $\begin{array}{c}25 \\
(1 \%)\end{array}$ & $\begin{array}{c}37.5 \\
(1.5 \%)\end{array}$ \\
\hline
\end{tabular}


Table 5: Mix Proportions for Cubic Meter Mix with Hybrid (1:2) Fibers (Kg)

\begin{tabular}{|c|c|c|c|}
\hline Index & $\mathrm{A}_{1}$ & $\mathrm{~A}_{2}$ & $\mathrm{~A}_{3}$ \\
\hline Cement & 950 & 950 & 950 \\
\hline Silica & 237.5 & 237.5 & 237.5 \\
\hline Sand & 950 & 950 & 950 \\
\hline Water & 190 & 190 & 190 \\
\hline Superplasticizer & $2 \%$ & $2 \%$ & $2 \%$ \\
\hline W/C & 0.2 & 0.2 & 0.2 \\
\hline w/c.m & 0.16 & 0.16 & 0.16 \\
\hline Steel Fiber & $\begin{array}{c}75 \\
(1 \%)\end{array}$ & $\begin{array}{c}150 \\
(2 \%)\end{array}$ & $\begin{array}{c}225 \\
(3 \%)\end{array}$ \\
\hline Glass Fiber & $\begin{array}{c}12.5 \\
(0.5 \%)\end{array}$ & $\begin{array}{c}25 \\
(1 \%)\end{array}$ & $\begin{array}{c}37.5 \\
(1.5 \%)\end{array}$ \\
\hline
\end{tabular}

\subsection{Mixing of UHPC}

Concrete was batched according to the following procedure:

- All constituent materials were weighed.

- Premix (cement, silica fume, and sand only) was mixed in mixer pan for 2 minutes (Dry Mix) to break up any clumps.

- Then, half of water was added to premix slowly over the course for 1 minute.

- After 1 minute, the remaining water with all superplasticizer dosage was added to premix over the course for 3 minutes until UHPC changes from a dry powder to a thick paste.

- The fibers were mixed together then added slowly to the mix and continue running mixer for 2 minutes to ensure that the fibers are well dispersed.

\subsection{Curing of UHPC.}

Two different conditions were used for curing:

i. Standard curing (SC), where specimens were put in water at room temperature until test time.

ii. Thermal curing, where specimens were put in water at $70^{\circ} \mathrm{C}$, for 7,14 , and 28 days and then in water at room temperature until testing.

\subsection{Measurements}

The following properties were measured on hardened concrete specimens, after 1 day (for compression test only), 7,14 , and 28 days.

i. Compressive strength on cube specimens (50x50x50 mm)

ii. Flexural strength by one central loading test on prisms specimens (40x40x160 mm).

iii. Splitting tensile strength by applying a uniform line load on a cylinder (50x100mm) (Brazilian Test).

\section{Results and Discussion}

The effect of different parameters on UHPC is discussed here below. The results are shown in Tables 6 and 7.

\subsection{Effect of Curing Condition}

One of the primary focuses of this research was to determine the effect of different curing conditions on the mechanical properties of UHPC. To discuss this effect, a comparison was made between standard and thermal curing on different mechanical properties, i.e. compressive, flexural, and tensile strengths. Table 6 shows the test ressults obtained for standard and thermal curing. Figures 1, 2, 3, 4, 5, and 6 show the effect of thermal and standard curing on the development of mechanical properties of UHPC. It can be seen that thermal curing for 28 days gives the best results as it is higher than standard curing by $35 \%$ for mixes $\mathrm{P}$, and $39 \%$ for mixes $\mathrm{R}$ and $\mathrm{A}$ in compressive strength, while in tension, the ratios were $9 \%, 11 \%$, and $17 \%$ for mixes $\mathrm{P}$, $\mathrm{R}$, and $\mathrm{A}$, respectively. In flexural strength it is higher by $16 \%, 12 \%$, and $17 \%$ for mixes $\mathrm{P}, \mathrm{R}$, and $\mathrm{A}$, respectively. From the shown data, after thermal curing, the UHPC is improved in terms of strength, and stiffness. UHPC gains strength and stiffness quickly at early ages, while also becoming much less ductile with large decrease in strain at peak loads. Specifically, the compressive strength and stiffness after 24 hours are ranged from 52.3 MPa to 60.3 $\mathrm{MPa}$. After 7 days, this value increased to over $109 \mathrm{MPa}$, and $77 \mathrm{MPa}$, with thermal curing and standard curing. It seems that thermal curing accelerates the pozzolanic reaction and accelerates the development of flexural and tensile strength. So thermal curing is directly proportional with development of flexural and tensile strength. 
Table 6: Tests Results

\begin{tabular}{|c|c|c|c|c|c|c|c|c|c|c|c|}
\hline \multirow{2}{*}{ Mix } & \multirow{2}{*}{ Curing } & \multicolumn{4}{|c|}{ Compres sive strength (MPa) } & \multicolumn{3}{|c|}{ Fle xu ral strength ( $\mathrm{MPa}$ ) } & \multicolumn{3}{|c|}{ Tensile strength ( $\mathrm{MPa}$ ) } \\
\hline & & 1 & 7 & 14 & 28 & 7 & 14 & 28 & 7 & 14 & 28 \\
\hline \multirow{2}{*}{ M } & $\mathrm{S} \mathrm{C}$ & 52.3 & 77 & 85 & 100 & 12.2 & 13.5 & 13.95 & 4.35 & 5.36 & 6.62 \\
\hline & $\mathrm{W}_{28} \mathrm{C}$ & 52.3 & 89.3 & 105.3 & 133.87 & 13.55 & 14.45 & 15.35 & 4.62 & 5.87 & 7.43 \\
\hline \multirow{2}{*}{$\mathrm{P}_{1}$} & S C & 60.5 & 80 & 87.3 & 106 & 13.05 & 14.45 & 15.3 & 5.11 & 6.5 & 7.21 \\
\hline & $\mathrm{W}_{28} \mathrm{C}$ & 60.5 & 97 & 119 & 143.5 & 13.93 & 15.5 & 16.3 & 6.08 & 6.75 & 7.75 \\
\hline \multirow{2}{*}{$\mathrm{P}_{2}$} & $\mathrm{~S} \mathrm{C}$ & 73 & 83 & 100 & 115.3 & 14.45 & 15.9 & 16.8 & 6.62 & 7.24 & 7.89 \\
\hline & $\mathrm{W}_{28} \mathrm{C}$ & 73 & 105 & 135 & 155.7 & 14.95 & 17.3 & 19.65 & 7.35 & 7.89 & 8.4 \\
\hline \multirow{2}{*}{$\mathrm{P}_{3}$} & $\mathrm{~S} \mathrm{C}$ & 78 & 89 & 105 & 123.5 & 16.35 & 18.75 & 20.1 & 8.2 & 9.4 & 10.24 \\
\hline & $\mathrm{W}_{28} \mathrm{C}$ & 78 & 117.5 & 148 & 170 & 17.78 & 19.3 & 21 & 9.48 & 10.23 & 11.14 \\
\hline \multirow{2}{*}{$\mathrm{R}_{1}$} & $\mathrm{~S} \mathrm{C}$ & 62.3 & 79 & 93.5 & 111.3 & 13.05 & 14.95 & 16.82 & 5.55 & 7 & 7.75 \\
\hline & $\mathrm{W}_{28} \mathrm{C}$ & 62.3 & 98 & 110 & 142 & 14 & 16.35 & 18.2 & 6.55 & 7.2 & 8 \\
\hline \multirow{2}{*}{$\mathrm{R}_{2}$} & S C & 67 & 90 & 101.5 & 110 & 15.4 & 16.35 & 18.2 & 7 & 8 & 8.56 \\
\hline & $\mathrm{W}_{28} \mathrm{C}$ & 67 & 102 & 120 & 153 & 15.9 & 18.2 & 20.1 & 7.75 & 8.75 & 9.2 \\
\hline \multirow{2}{*}{$\mathrm{R}_{3}$} & S C & 70 & 87 & 102.5 & 120 & 16.8 & 18.2 & 19 & 9.23 & 10.5 & 11.3 \\
\hline & $\mathrm{W}_{28} \mathrm{C}$ & 70 & 109 & 125 & 175 & 18.2 & 20.1 & 21.35 & 10.89 & 11.75 & 12.5 \\
\hline \multirow{2}{*}{$A_{1}$} & $\mathrm{~S} \mathrm{C}$ & 67 & 85 & 100 & 114.5 & 14 & 15.9 & 16.8 & 5.36 & 6.55 & 7.2 \\
\hline & $\mathrm{W}_{28} \mathrm{C}$ & 67 & 97.5 & 122 & 150 & 14.45 & 16.35 & 19.65 & 6.65 & 7.35 & 8.45 \\
\hline \multirow{2}{*}{$\mathrm{A}_{2}$} & S C & 70 & 92 & 103 & 117 & 14.45 & 17.3 & 19.15 & 7.5 & 8.75 & 9.3 \\
\hline & $\mathrm{W}_{28} \mathrm{C}$ & 70 & 105.5 & 125 & 160 & 15.9 & 17.75 & 22.5 & 8.56 & 9.2 & 10.49 \\
\hline \multirow{2}{*}{$\mathrm{A}_{3}$} & S C & 75 & 82.5 & 108 & 127.5 & 17.3 & 19.15 & 20.6 & 10.56 & 11 & 11.25 \\
\hline & $\mathrm{W}_{28} \mathrm{C}$ & 75 & 125 & 156 & 180 & 17.75 & 21.5 & 23.56 & 11.25 & 12 & 12.75 \\
\hline
\end{tabular}

M: Control mix.

P: Mixes with steel fiber.

R: Mixes with hybrid fiber (glass: steel; $1: 1$ ).

A: Mixes with hybrid fiber (glass: steel; 1:2).

Table 7: Strength at 28 days for all curing conditions

\begin{tabular}{|c|c|c|c|c|c|c|c|c|c|c|c|c|}
\hline \multirow{2}{*}{ Mix } & \multicolumn{4}{|c|}{ Compressive strength ( $\mathrm{MPa}$ ) } & \multicolumn{4}{|c|}{ Fle xu ral strength ( $\mathrm{MPa})$} & \multicolumn{4}{|c|}{ Tensile strength ( $\mathrm{MPa}$ ) } \\
\hline & $\mathrm{S} \mathrm{C}$ & $\mathrm{W}_{7} \mathrm{C}$ & $\mathrm{W}_{14} \mathrm{C}$ & $\mathrm{W}_{28} \mathrm{C}$ & $\mathrm{S} \mathrm{C}$ & $\mathrm{W}_{7} \mathrm{C}$ & $\mathrm{W}_{14} \mathrm{C}$ & $\mathrm{W}_{28} \mathrm{C}$ & $\mathrm{S} \mathrm{C}$ & $\mathrm{W}_{7} \mathrm{C}$ & $\mathrm{W}_{14} \mathrm{C}$ & $\mathrm{W}_{28} \mathrm{C}$ \\
\hline M & 100 & 110.5 & 122 & 133.87 & 13.95 & 14.56 & 14.95 & 15.35 & 6.62 & 6.74 & 7.24 & 7.43 \\
\hline $\mathrm{P}_{1}$ & 106 & 115 & 133.8 & 143.5 & 15.3 & 15.7 & 15.9 & 16.3 & 7.21 & 7.45 & 7.6 & 7.75 \\
\hline $\mathrm{P}_{2}$ & 115.3 & 129 & 142 & 155.7 & 16.8 & 17.4 & 18.12 & 19.65 & 7.89 & 8 & 8.12 & 8.4 \\
\hline $\mathrm{P}_{3}$ & 123.5 & 140 & 151 & 166 & 20.1 & 20.35 & 20.85 & 21 & 10.24 & 10.61 & 10.95 & 11.14 \\
\hline $\mathrm{R}_{1}$ & 111.3 & 119 & 131.4 & 142 & 16.82 & 17 & 17.34 & 18.2 & 7.75 & 7.75 & 7.85 & 8 \\
\hline $\mathrm{R}_{2}$ & 110 & 128 & 140 & 153 & 18.2 & 18.67 & 19.28 & 20.1 & 8.56 & 8.85 & 9.05 & 9.2 \\
\hline $\mathrm{R}_{3}$ & 120 & 138 & 155.3 & 162 & 19 & 19.89 & 20.75 & 21.35 & 11.3 & 11.75 & 12.13 & 12.5 \\
\hline $\mathrm{A}_{1}$ & 114.5 & 127 & 138 & 150 & 16.8 & 17.38 & 18 & 19.65 & 7.2 & 7.65 & 8.24 & 8.45 \\
\hline$A_{2}$ & 117 & 132.5 & 138.3 & 160 & 19.15 & 20 & 21.18 & 22.5 & 9.3 & 9.65 & 10.15 & 10.49 \\
\hline $\mathrm{A}_{3}$ & 127.5 & 145 & 169 & 178 & 20.6 & 21.56 & 22.7 & 23.56 & 11.25 & 11.67 & 12.4 & 12.75 \\
\hline
\end{tabular}

$\mathrm{W}_{7} \mathrm{C}$ : Specimens were put in water at $70^{\circ} \mathrm{C}$ for 7 days then transmitted to water at room temperature until test time. $\mathrm{W}_{14} \mathrm{C}$ : Specimens were put in water at $70^{\circ} \mathrm{C}$ for 14 days then transmitted to water at room temperature until test time. $\mathrm{W}_{28} \mathrm{C}$ : Specimens were put in water at $70^{\circ} \mathrm{C}$ for 28 days. 


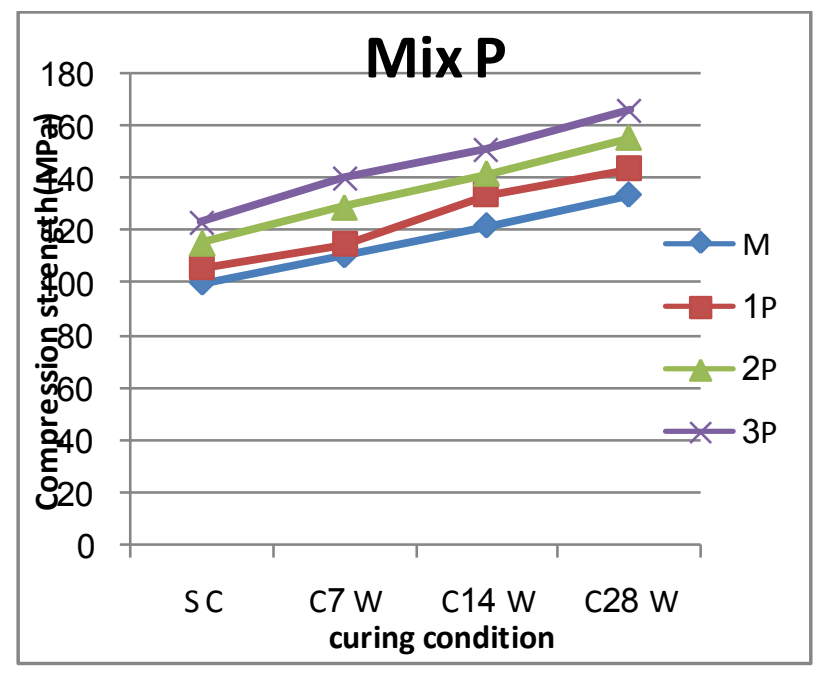

Fig.1. Compressive strength after 28 days for different periods of thermal curing for concrete with steel fiber.

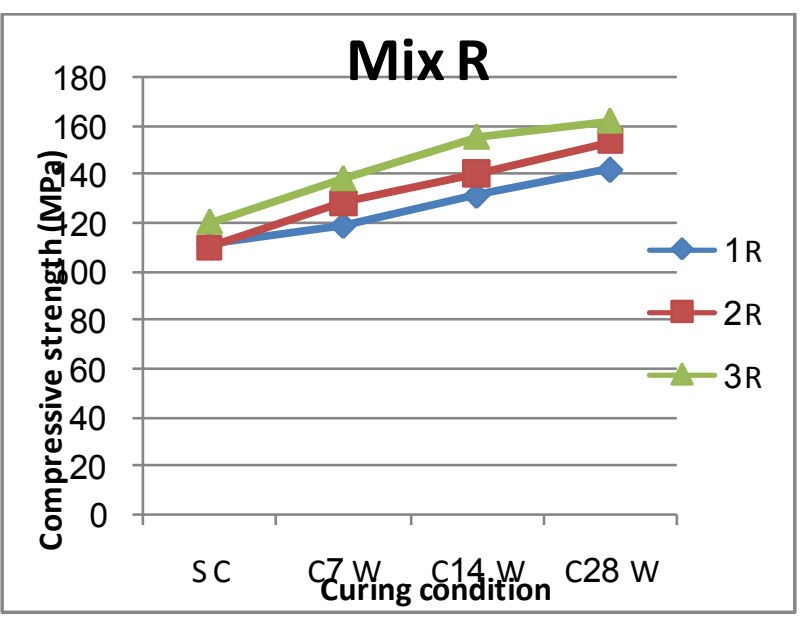

Fig. 2. Co mp ressive strength after 28 days for different periods of thermal curing.

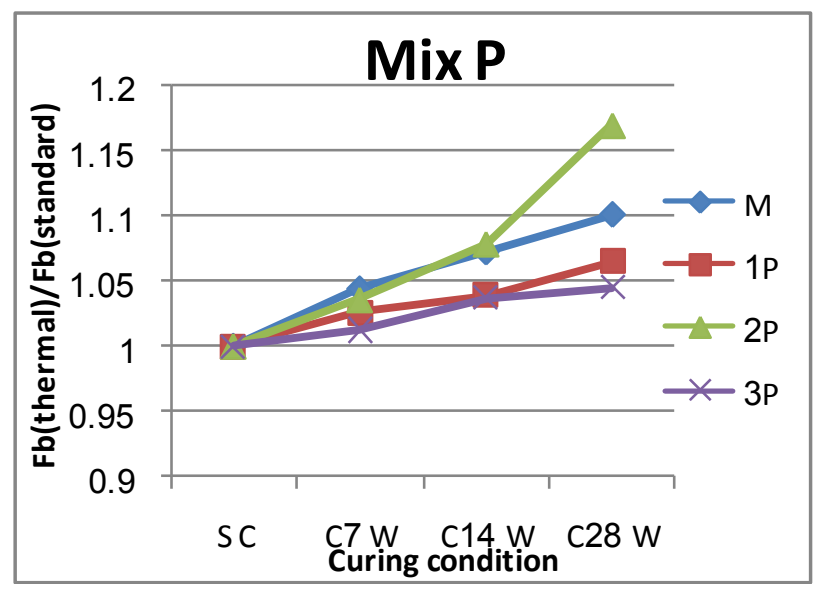

Fig. 3. Comparis on between different periods of thermal curing on the flexural strength at 28 days.

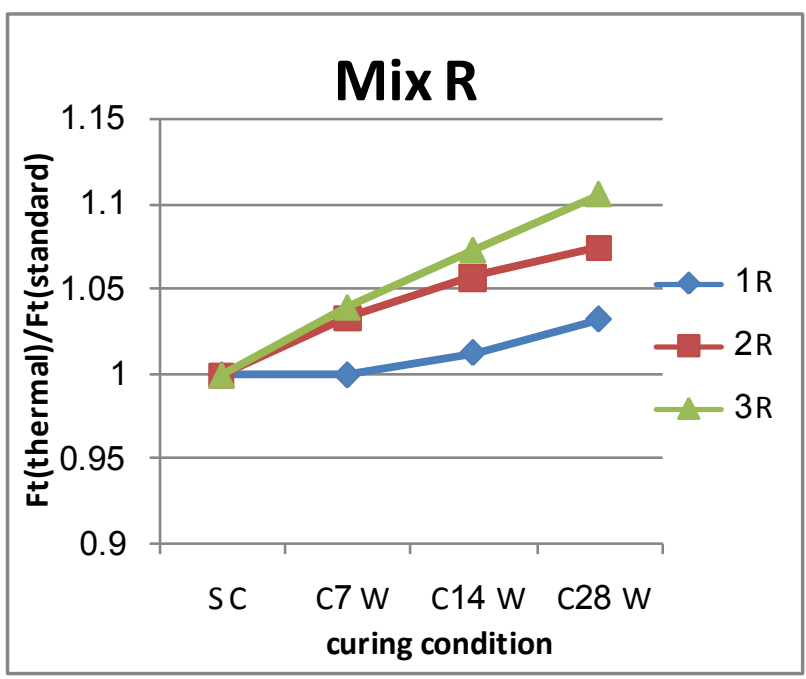

Fig.4. Comparison between different periods of thermal curing on the flexure strength at 28 days.

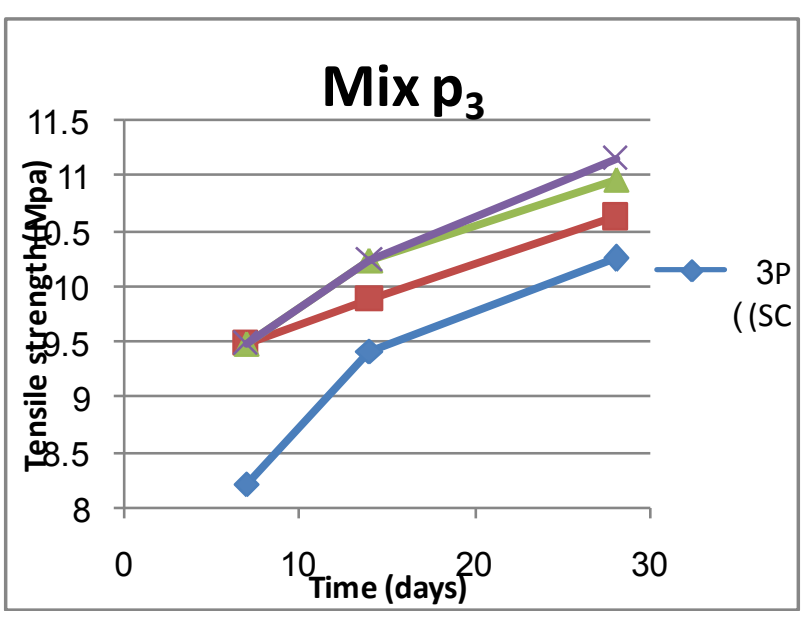

Fig.5. Comparis on between the tensile strength development under standard and thermal curing.

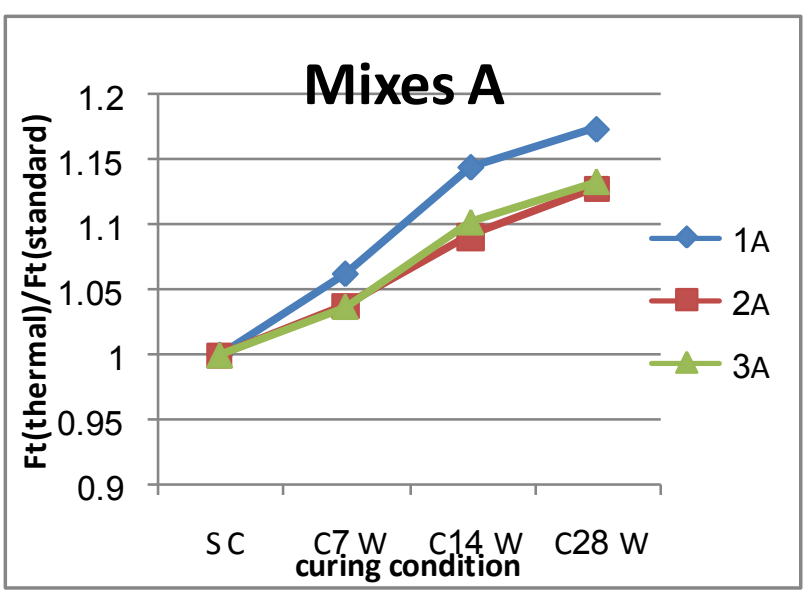

Fig.6. Comparis on between different periods of thermal curing on the tensile strength at 28 days. 


\subsection{Effect of Steel Fibers.}

Figures 7, 8, 9, and 10 shown below represent the effect of steel fibers on the mechanical properties of UHPC. Where the compressive strength $f_{c}$ varies for each mix and different age. The ratio between $f_{c}$ with and without fibers is slightly larger after 1 day and the rate of development of this ratio decreased gradually with time at 7,14 , and 28 days in thermal curing rather than in standard curing. It can be concluded that in early ages, concrete did not gain enough strength to resist the applied loads, so steel fibers played an important role in resisting the applied stresses. The pervious data show that steel fiber had a great effect on the compressive strength and these results were confirmed by Jian xin Ma [11], Rossi [12], Graybeal and Hartmann [13], while this opinion was not agreed with Altoubat and Lang [14] that was the compressive strength of UHPC is slightly affected by the presence of fibers. On the other hand in flexural strength $\left(f_{b}\right)$, the ratio between $f_{b}$ with and without steel fibers is slightly larger after 7 day and increased gradually with time at 14 , and 28 days. It can be concluded that, the fiber effect in standard curing is higher than in thermal curing. For the tensile strength $\left(f_{t}\right)$, the effect of steel fibers is high at early ages and decreases after 14 and 28 days. As at 7 days, it increased by $89 \%$ and $100 \%$, and at 28 days it increased by $55 \%$ and $50 \%$, for standard and thermal curing respectively.

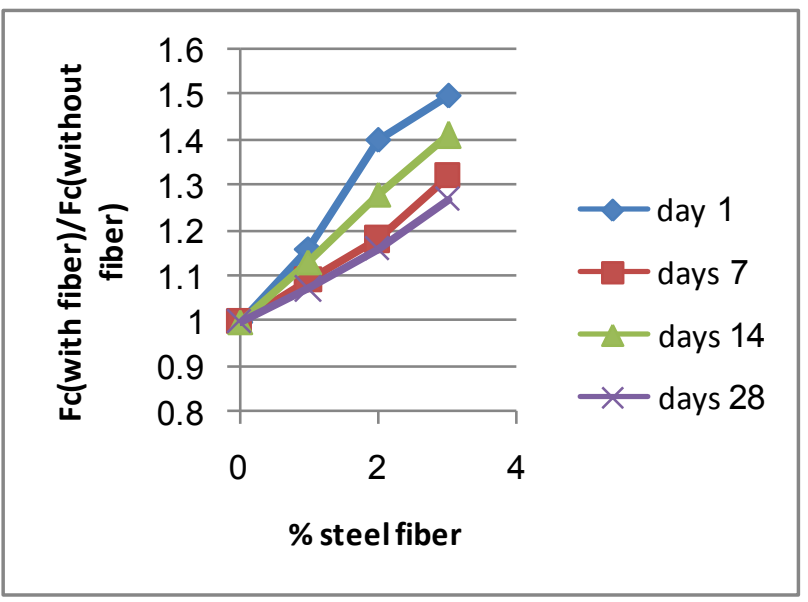

Fig.7. Effect of steel fiber on compressive strength with thermal curing.

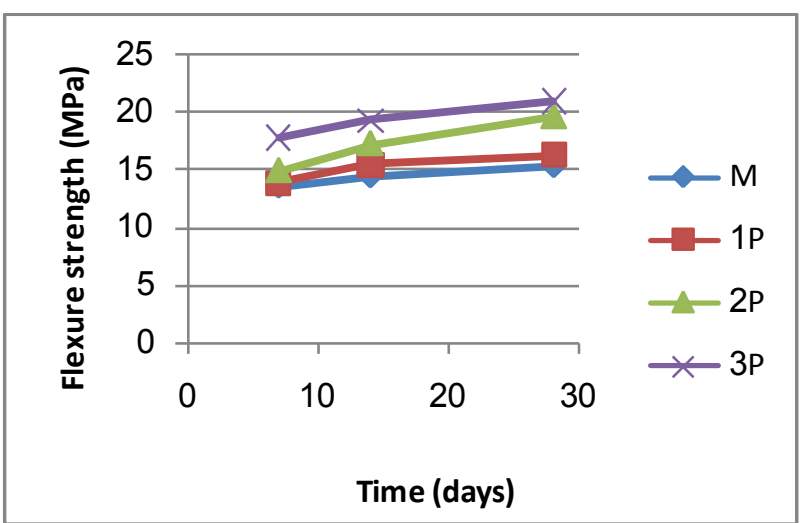

Fig.8. Development of flexural strength for mixes with steel fiber with thermal curing.

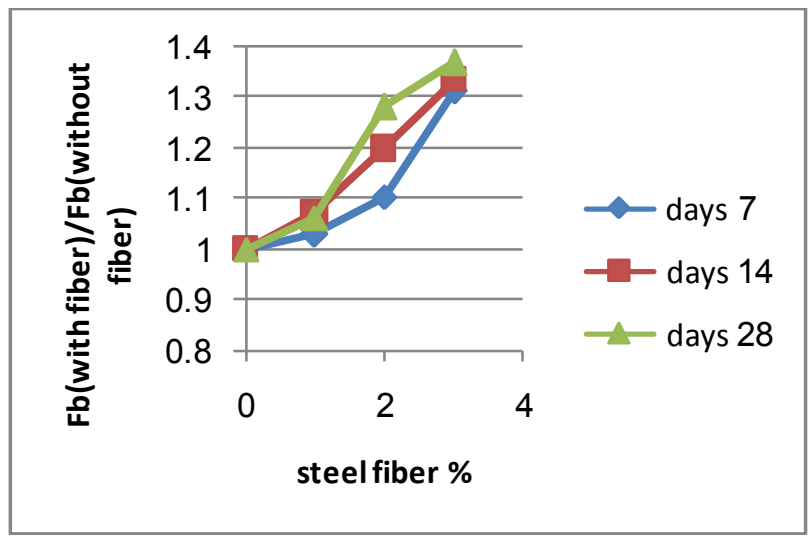

Fig.9. Effect of steel fibers on fle xu ral strength with thermal curing.

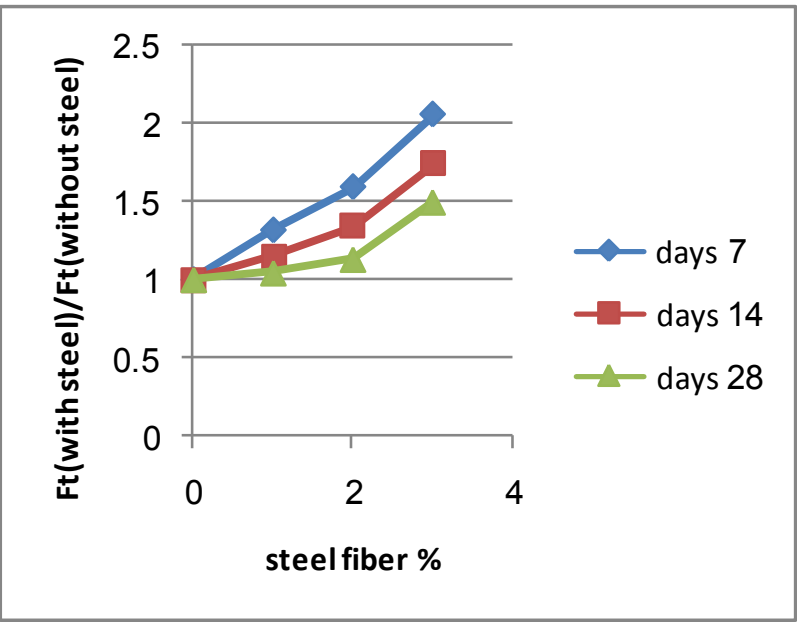

Fig. 10. Effect of steel fibbers on tensile strength for thermal curing. 
Adding hybrid Fibers with ratio 1:1 tends to improve the mechanical properties of UHPC, as it is found to increase the compressive strength by $20 \%, 30 \%$ and flexural strength by $36.6 \%, 39 \%$, for standard and thermal curing respectively. The highest improvement was in tensile strength by $68 \%, 71 \%$ in standard and thermal curing respectively. In mixes (R), glass fiber was used by replacing $50 \%$ of steel fiber in mixes P. Figures 11,12 , and 13 show comparis on between the effect of hybrid fiber and steel fiber. The data shows that the use of hybrid fiber (glass-steel) with ratio (1:1) instead of steel fiber generally does not improve the compressive strength, but it has negative effect on compressive strength by $1 \%$ at early ages. But it improves flexural strength by $11 \%, 2 \%$, and $1.6 \%$ for fiber content $1 \%$, $2 \%$, and $3 \%$, respectively, at 28 days in thermal curing. For the tensile strength, it can be seen that hybrid fiber is better than steel fiber especially at 7days as it reaches $15 \%$, and $13 \%$ for thermal and standard curing respectively for mix $R_{3}$. This improvement decreases gradually by time that reaches $10 \%$, and $12 \%$ for thermal and standard curing respectively for mix $R_{3}$.

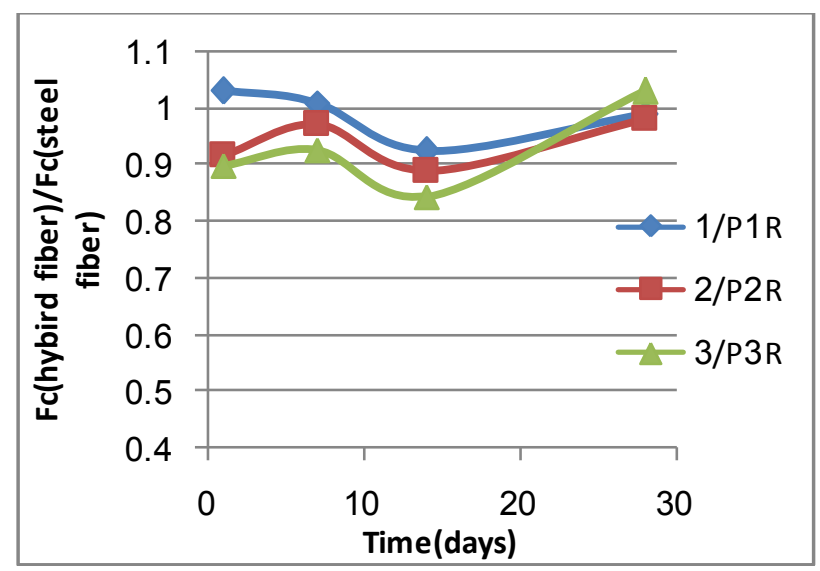

Fig. 11. Comparis on between the effect of hybrid fiber and steel fiber for thermal curing on compressive strength.

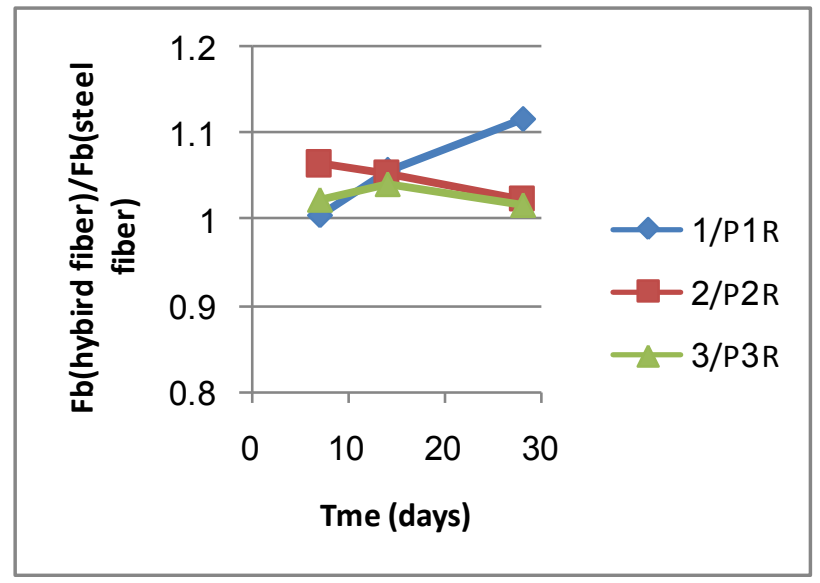

Fig. 12. Comparis on between the effect of hybrid fiber and steel fiber for thermal curing on flexural strength.

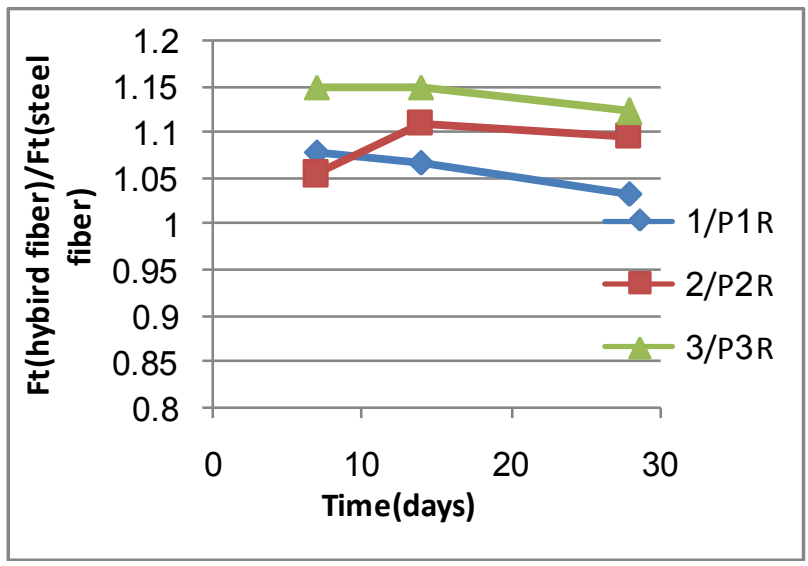

Fig. 13. Comparis on between the effect of hybrid fiber and steel fiber for thermal curing on tensile strength.

\subsubsection{Hybrid Fiber with Ratio (1:2).}

Adding hybrid Fibers with ratio 1:2 increases the compressive strength by $27 \%, 34 \%$ and fle xural strength by $47.6 \%, 53.5 \%$, for standard and thermal curing respectively. The highest improvement was in tensile strength by $70 \%, 72 \%$ in standard and thermal curing respectively. In mixes (A), glass fiber was used by adding $50 \%$ of steel fiber in mixes P. Figures 14,15 , and 16 show comparis on between the effect of hybrid fiber $(1: 2)$ and steel fiber. It can be seen that hybrid fiber is better than steel by $6 \%$ in compressive strength, at 28 days. For flexural strength, hybrid fiber is better by $20 \%$, $3 \%$, and $6 \%$ for $A_{1}, A_{2}$, and $A_{3}$, respectively. For the tensile strength mixes, $\mathrm{A}$ is better by $9 \%, 25 \%$, and $14 \%$ for $A_{1}, A_{2}$, and $A_{3}$, respectively.

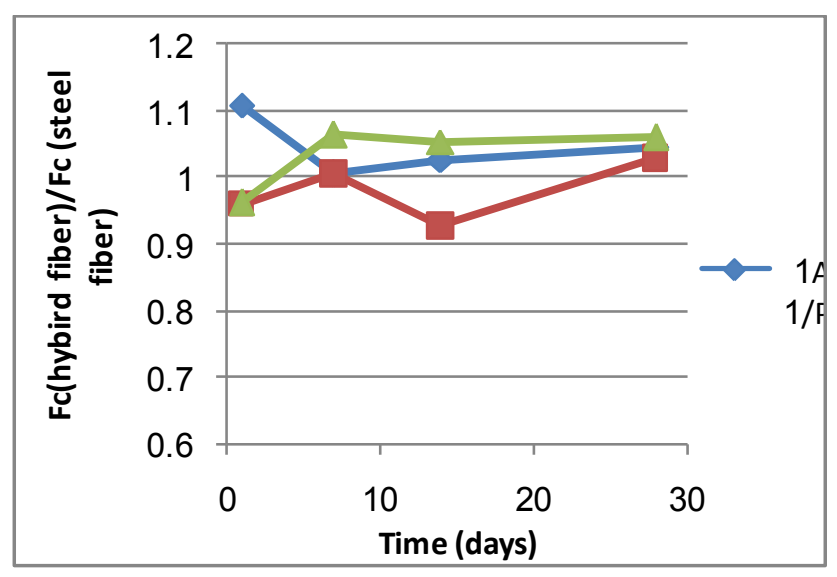

Fig. 14. Co mparis on between the effect of hybrid fiber and steel fiber for thermal curing on compressive strength. 


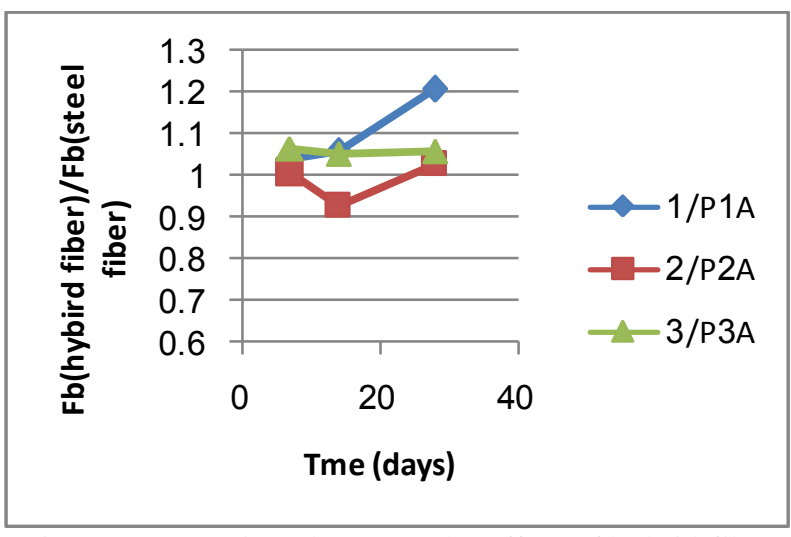

Fig. 15. Co mparis on between the effect of hybrid fiber and steel fiber for thermal curing on flexu ral strength.

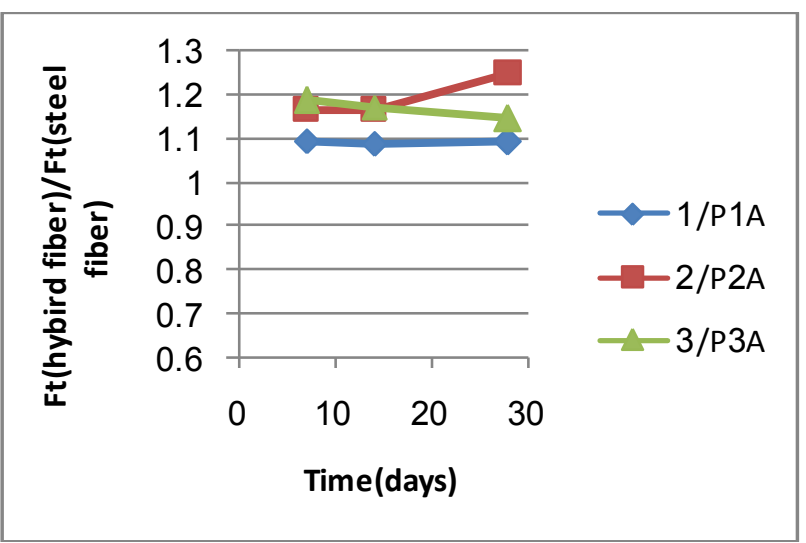

Fig. 16. Comparis on between the effect of hybrid fiber and steel fiber for thermal curing on tensile strength.

\section{Conclusions}

The following conclusions are based on the research presented in this paper;

1. As the thermal curing applied to specimens after placing concrete in mould by 24 hours, the mechanical properties of UHPC tends to be improved compared to standard curing.

2. The partial replacement of steel fibers with glass fibers, did not affect the compressive strength, whereas the flexural and tensile strengths are increased by $11 \%$ and $9 \%$ respectively with thermal curing condition.

3. Adding glass fiber to steel fiber for thermal curing condition increases the compressive strength by $6 \%$, the flexural and tensile strengths by $20.5 \%$ and $25 \%$ respectively.

4. The 1-day compressive strength of UHPC reached $75 \mathrm{MPa}$ with hybrid fiber content of $4.5 \%$ by volume. Thus, the construction time can be minimized by using UHPC.

\section{References:}

1. Shah, S. P., Nov.-Dec. 1991 "Do Fibers Increase The Tensile Strength of Cement-Based Matrixes?" ACI Material journal, vol.88, no.6.
2. Marko Orgass, Yvette Klung, 2004 "Steel Fiber Reinforced Ultra-High Strength Concrete", Lacer No.9.

3. Steven H. Kosmtka, Beatrix Kerhoff, and William C. Panarese, 2003 "Design and Control of Concrete Mixtures", Fourteenth edition, Portland Cement Association.

4. Altoubat Salah A., and Lange David A., July August 2001 "Creep, Shrinkage and Cracking of Restrained Concrete at Early Age", ACT Material Journal, A merican Concrete Institute, Farmington Hills, Michigan.

5. Ganesh Babu. K and Pavan Kumar. D, 2004, 8-10 Jan., Chennai "Behaviour of Glass Fiber Reinforced Cement Composites", ICFRC International Conference on Fiber Composites, High Performance Concretes and Smart Materials.

6. J. A. O. Barros, J. A. Figueiras, 2001 "Flexural behaviour of steel fiber reinforced concrete" $\mathrm{PhD}$ dissertation, Civil Eng. Dept., Faculty of Engineering, University of Porto, Portugal.

7. Kollmorgen, G. A. 2004," Impact of Age and Size on the Mechanical Behaviour of Ultra-High Performance Concrete." M.Sc. Thesis in Civil Engineering, Michigan Technological University, Houghton, Michigan.

8. loukili, A., richard, P, and lamirrault, J., 1998 "A Study on Delayed Deformations of An Ultra High Strength Cementitious Material ." Recent Advanced in concrete Technology: proceedings: forth CANMET/ACI/JCI/ international Conference: 136 Tokushima, japan, SP-179, AMERICAN Concrete institute, Farmington Hills MI, PP. 929949.

9. Graybeal, B., June 2006, "Nation's First Ultra High Performance Concrete Bridge Opens in Lowa.", Research\& Technology Transporter, FHWA.

10. Richarb, P. And Cheyrezy, M.H., 1994" Reactive Powder Concretes with High Ductility and 200-800 MPa Compressive Strength". Concrete Technology, Past, Present, and Future, Proceedings of tzexpansive Ultra High Strength V.Mohan Malhotra Symposium, ACI SP -144, S. Francisco, pp. 507-518. Editor; P.K. Mehta

11. Jianxin Ma, 2001 "Experimental Investigation for the Production of Ultra- High Strength Concrete", Lacer 6, pp 215-228.

12. Rossi, P., 2001, "Ultra-High-Performance-A French perspective on approaches used to produce high-strength, ductile fiber reinforced concrete", In: Concrete International, pp.46-52, 12.2

13. Graybeal, B.A., and Hartmann, J.L., 2003 "Strength and Durability of Ultra-High Performance Concrete," $3^{\text {rd }}$ International Symposium on High Performance Concrete, PCI, Orlando, Florida.

14. Altoubat Salah A., and Lange David A., JulyAugust 2001 "Creep, Shrinkage and Cracking of Restrained Concrete at Early Age", ACI Material Journal, A merican Concrete Institute, Farmington Hills, Michigan. 


\begin{tabular}{|c|ccc|c|}
\hline & PORT SAID ENGINEERING RESEARCH JOURNAL \\
\hline
\end{tabular}

\title{
Single beam bathymetric data modelling techniques for accurate maintenance dredging
}

\author{
Ahmed I. EL-Hattab ${ }^{1}$
}

\begin{abstract}
The main components of most ports are approach channels, , turning basins, berthing channels, quay walls, utilities and handling equipments. All these components require regular maintenance. The most expensive part of which is the maintenance of the water components i.e. the approach channels, turning basins and the berthing channels which are subject to continuous siltation. Such siltation reduces the ultimate design depth required for the safe manoeuvring of the ships according to their drafts. The amount of siltation must be estimated prior to the start of dredging operations. This is done by modelling the data obtained from Bathy metric Surveying. Accurate Digital Terrain Modelling (DTM) of the data plays an important role in dredging processes, especially during maintenance operations where the quantities are relatively small and the unite price is relatively high compared with capital dredging. It is important to adopt an accurate and fast modelling technique.
\end{abstract}

In this study, twelve of digital terrain modelling interpolation techniques have been investigated to find out the most accurate and fastest techniques that can be applied during bathymetric survey phase of the maintenance dredging projects. The results showed that triangulated irregular network and natural neighbour interpolation techniques were the optimal choice since they produce the least root mean square error of $0.16 \mathrm{~m}$ at $10 \mathrm{~m}$ grid size. For real-time dig ital terrain modelling applications, it is concluded that triangulated irregular network technique could be used. It was the fastest interpolation technique where only 0.35 second is needed to create a model with $5 \mathrm{~m}$ grid size. Natural neighbour was the next fastest technique where 5.21 seconds were required to create the model.

\section{INTRODUCTION}

Most ports and harbours have dredged channels, berths and anchorages, which suffer from siltation, thereby reducing the depth of water available for navigation. Ports operate with a minimum under keel clearance that must be maintained by a ship transiting a port. Routine maintenance dredging refers to the removal of accumulated sediments from channel beds to maintain the design depths of existing public-use facilities. Given multiple sets of bathymetric survey data and modelling the seafloor levels, sediments volumes can be estimated to determine the level of sediments accumulation in a navigation channel. In general the layers thicknesses that will be removed during maintenance dredging are small. Therefore, accurate determination and modelling of the seafloor levels is essential to avoid unnecess ary over-dredging and extra

costs. The required accuracy is increased and becomes critical in case of environmental dredging of contaminated sediments. At which, accurate removal of the required layers without excessively removing clean material is significant for cost-effective environmental dredging.

\footnotetext{
${ }^{1}$ Faculty of Engineering, Port Said University, Port Said, Egypt
}

Depths are normally measured using either single-beam (SBES) or multi-beam (MBES) echo sounders. SBES is still the most common tool used in port and harbour surveys and will continue to give valid results when used correctly in a well planned and executed survey (FIG 2010). The SBES, as soundings, are only acquired directly underneath the transducer. Survey lines run perpendicular to the underwater slopes and the line spacing between the survey lines is dependent on the scale of the final product and the required resolution. Tie lines (longitudinal lines) are run perpendicular to the primary survey lines but at wider spacing and act as a quality assurance cross-check on the acquired field data. The major disadvantage of a SBES is that it illuminates only a narrow portion of the seafloor. Also the levels between survey lines will be omitted from the bathymetric data, while MBES can provide continues coverage as shown in Figure (1). Consequently, accurate modelling bathymetric models are crucial to interpolate the levels and fill the gap between the survey lines.

Digital terrain models (DTM) with regular grid are used for determining the bathymetric model which is defined as "a digital representation of the topography (bathymetry) of the seafloor by coordinates and depths" (IHO 2008).To determine the model, it is 
important to select the gridding interpolation technique, which directly affects the DTM uncertainty.

Several of previous comparative studies have examined the effects of interpolation techniques based on applications in a range of disciplines (e.g. Erdogan 2009; Weng., Yang et al. 2004, and Yanalak 2003, Kravchenko 1999). Each study concluded different techniques to be the suitable ones for their applications. However, the main objectives of this study are:

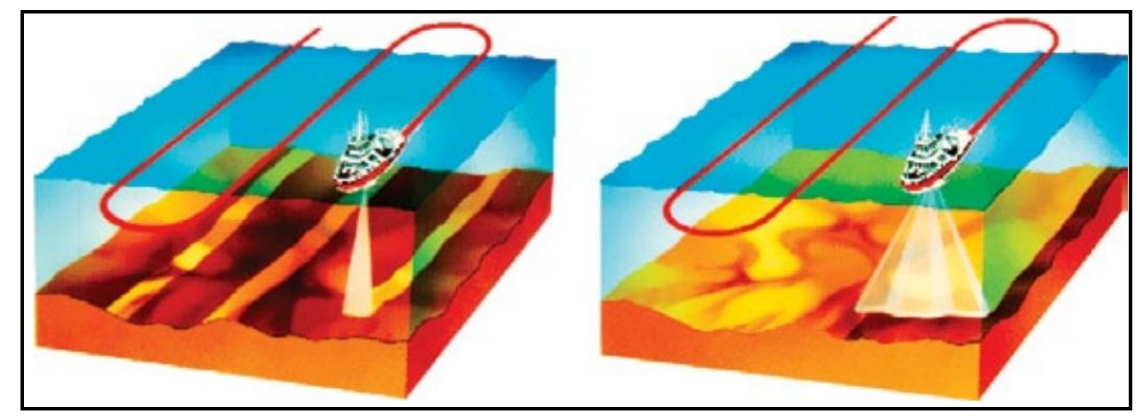

Figure (1) Coverage of single-beam and mu lti-beam echo sounders

(Kearns and Breman, 2010).

i. To evaluate the applied interpolation techniques on the uncertainty of DEM generation for SBES bathymetric data.

ii. To conclude the most accurate techniques that can be applied during maintenance dredging project.

iii. To determine the suitable interpolation techniques for real-time DTM generation.

\section{DTM INTERPOLATION TECHNIQUES}

In this research, twelve of traditional interpolation techniques were tested for their effectiveness to predict depths in the non-surveyed areas between SBES cross lines. These interpolations techniques can be describe as follows:

a) Inverse distance to a power (IDP)

This technique is a weighted average interpolator and a deterministic interpolation method in which values at unsampled points are estimated from known points using a weight function in a search neighbourhood. Known values are used to determine unknown values surrounding each data point. Points closer to the predicted point have more influence than points of far distance. The IDP is one of the simpler interpolation techniques as it does not require pre-modelling like the kriging technique (To mc zak, 1998).

b) $\operatorname{Kriging}(\mathrm{KRG})$

It is a stochastic technique uses a linear combination of weights at known points to estimate the value at an unknown point. It builds these inferences and estimates using a semivariogram which is a measure of spatial correlation between two points. Weights are given to points that have similar directional influence and distance. A semivariogram bases these predictions by the level of spatial autocorrelation, that is, dependence between sample data values which decrease as the distance between observations increase (Lam 1983).

c) Minimu m curvature (MCV)

This technique involves the fitting of traditional interpolation two-dimensional splines to the observed data. Spline interpolates a surface from points using a minimum curvature spline technique. The basic form of the minimu m curvature Spline interpolation imposes two conditions; the surface must pass exactly through the data points also the surface must have minimum curvature. The basic minimum curvature technique is also referred to as thin plate interpolation. It ensures a smooth surface, together with continuous firstderivative surfaces. Rapid changes in gradient or slope may occur in the vicinity of the data points, therefore this model is not suitable for estimating second derivative (Kay et al 2000).

d) Modified Shepard's (MSP)

Shepard method is an interpolation method that creates a surface based on a weighted average of values at data points. The weight function is an inverse distance function of the data points. The Modified Shepard's Method uses an inverse distance weighted least squares method at which the weight function is designed to have local support and localized the overall approximation. This method can be either an exact or a smoothing interpolator (Thacker et al. 2009).

e) Natural neighbour (NTN)

Natural neighbour interpolation is a method of spatial interpolation. The method is based on Voronoi tessellation (dual of a Delaunay triangulation) of a discrete set of spatial points. This has advantages over simpler methods of interpolation, such as nearest neighbour, in that it provides a more smooth approximation to the underlying "true" function. The 
natural neighbour interpolation algorithm uses a weighted average of the neighbouring observations, where the weights are proportional to the "borrowed area". Also, the natural neighbour method does not extrapolate contours beyond the convex hull of the data locations (Bobach T. and Umlauf G 2007).

\section{f) Nearest neighbour (NEN)}

It is a simple method of multivariate interpolation in one or more dimensions. It finds the closest subset of input samples to a query point and assigns the value of the nearest point to each grid node. This method is useful when data are already evenly spaced (Sibson, 1981).

g) Polynomial regression (PRG)

Polynomial interpolation is an approximate, deterministic interpolation method that fits a mathematical function to the measured points. Options range from a first-order to higher-order polynomials. The predictive surface is typically generated by using a least-squares regression fit that minimize the squared differences between the surface and measured points. Because it is an approximate interpolator, the surface is not constrained to go through the measured points as with radial basis function interpolation. In addition, because the method generates the best fit between the measured points, it is unlikely that the fitted line will run outside the minimum or maximu measured value, except once it goes beyond the measured area as extrapolation (Eberly et al. 2004).

h) Radial basis function (RBF)

RBF methods are a series of deterministic exact interpolation methods. These methods are based on the assumption that the interpolation function should pass the data points, and at the same time, should be as smooth as possible RBFs minimize the total curvature of the surface. There are five different basis functions: Thin-plate spline, spline with tension, completely regularized spline, multi-quadric function, and inverse multi-quadric function. Each basis function has a different shape and results in a slightly different interpolation surface. However, the RBFs are local interpolation method capable of extrapolation. Also, RBFs are used for calculating smooth surfaces from a large nu mber of data points (Buhmann 2003).

i) Triangulated irregular network (TIN)

In this method, the optimal Delaunay triangulation is applied where the sample points are connected by lines to form triangles and within each triangle the surface is usually represented by a plane. By using triangles, it is ensured that each piece of the mosaic surface will fit with its neighbouring pieces. Thus, the surface will be continuous, as each triangle's surface would be defined by the elevations of the three corner points. The result is a patchwork of triangular faces over the extent of the grid. This method is an exact interpolator. Each triangle defines a plane over the grid nodes that lying within the triangle, with the tilt and elevation of the triangle determined by the three original data points defining the triangle. All grid nodes within a given triangle are defined by the triangular surface (ElSheimy et al. 2005).

\section{j) Moving average(MAV)}

This method assigns values to grid nodes by averaging the data within the grid node's search ellipse. For each grid node, the neighbouring data are identified by centring the search ellipse on the node. The output grid node value is set equal to the arithmetic average of the identified neighbouring data ( $\mathrm{Li}$ et al. 2005).

k) Data metrics (DMT)

The collection of data metrics method creates grids of information about the data on a node-by-node basis. Data metrics uses the local data set including break lines, for a specific grid node for the selected data metrics. The local data set is defined by the search parameters. Data metrics is used to provide information about the data. After information is obtained from data metrics, the data can be interpolated using one of the other gridding methods (Yang 2004).

\section{1) Local polynomial (LPL)}

The local polynomial interpolation method assigns values to grid nodes by using a weighted least squares fit with data within the grid node's search ellipse. For each grid node, the neighbouring data are identified within the search area. Using only these identified data, a local polynomial is fit using weighted least squares, and the grid node level is set equal to this value (Rawlings 1998).

\section{3- EVALUATION OF DTM UNCERTAINTY}

The source of data in this study was the bathymetric data of Port Said East Port (PSEP) maintenance project, which was carried out during the period of April 2008 to March 2010. Figure (2) shows an example of cross sections of the port navigation channel before and after the maintenance dredging. 


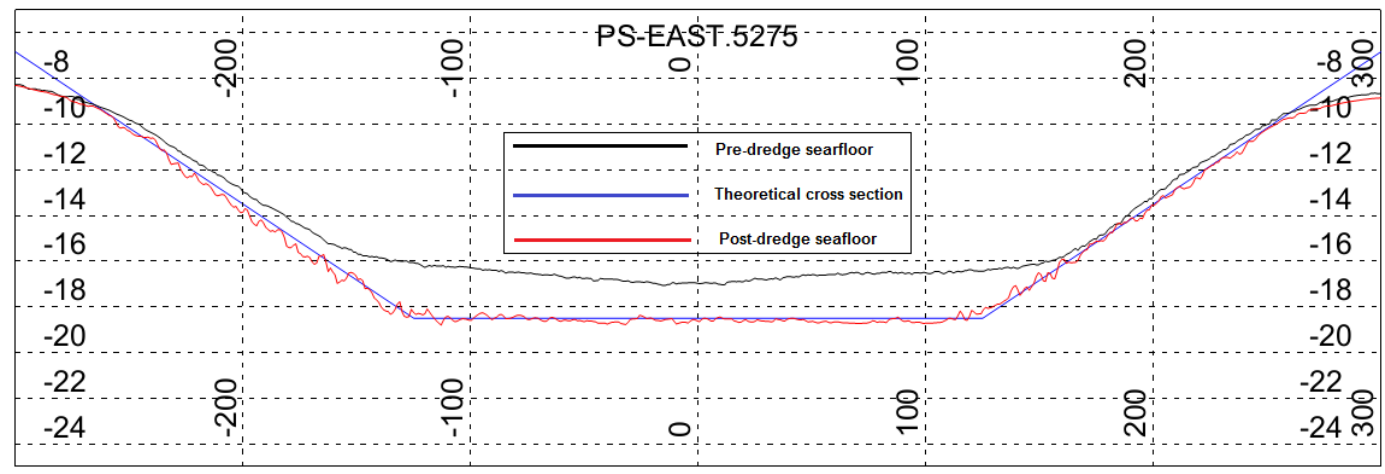

Figure (2) Cross section of PSEP navigation channel

There are number of methods that can be applied to validate the DTM of the seafloor, however two of them were applied in this study. The first method is the use of an independent set of sample data that is never used in the interpolation process. For each point, the deviation between the actual and predicted values is calculated, and uncertainty is then tested according to these values. The longitudinal survey lines (check lines), as shown in Figure (3), have been used to evaluate the DTM interpolation techniques.

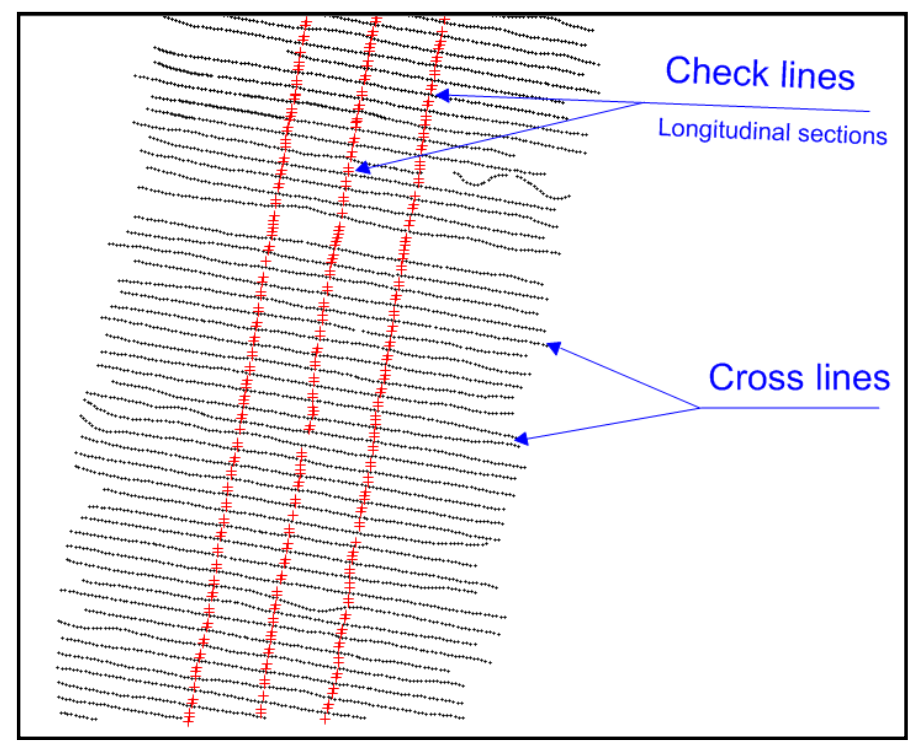

Figure (3) Locations of the check lines for bathymetric survey

Check lines crossing the regular lines are always done to confirm the accuracy of the positioning, the depth measurement, and other depth corrections. They are run as close to collected using an independent system, different survey vessel and/or time, and on a rough bottom. Practically, the comparis on of the check line soundings over a DTM generated from the regular lines on a relatively flat bottom is a good way to obtain difference values. When discrepancies exceed the perpendicular to the principal lines as possible. The differences between principal lines and check lines have to fall within the limits of the survey order. If possible, check lines may be permissible amount, the soundings must be carefully examined to determine the possible sources of error: tide or water level, sea state, beam angle, position errors, calibration errors, corrections used, etc. Once the sources of error have been determined, corrective action must be taken. This work should be done as soon as 
possible as the survey progresses. In some cases, it may be necessary to resurvey the portion of the area that is subject to disagreement with the check lines (CHS 2005). The other applied evaluation method that has been used in the current study was the splitsample method. In this method, some raw data were omitted as shown in Figure (4), interpolation was performed, and then the differences between the predicted and measured values of the omitted data were calculated. These differences have been used as a measure of the stability of the interpolation algorithm.

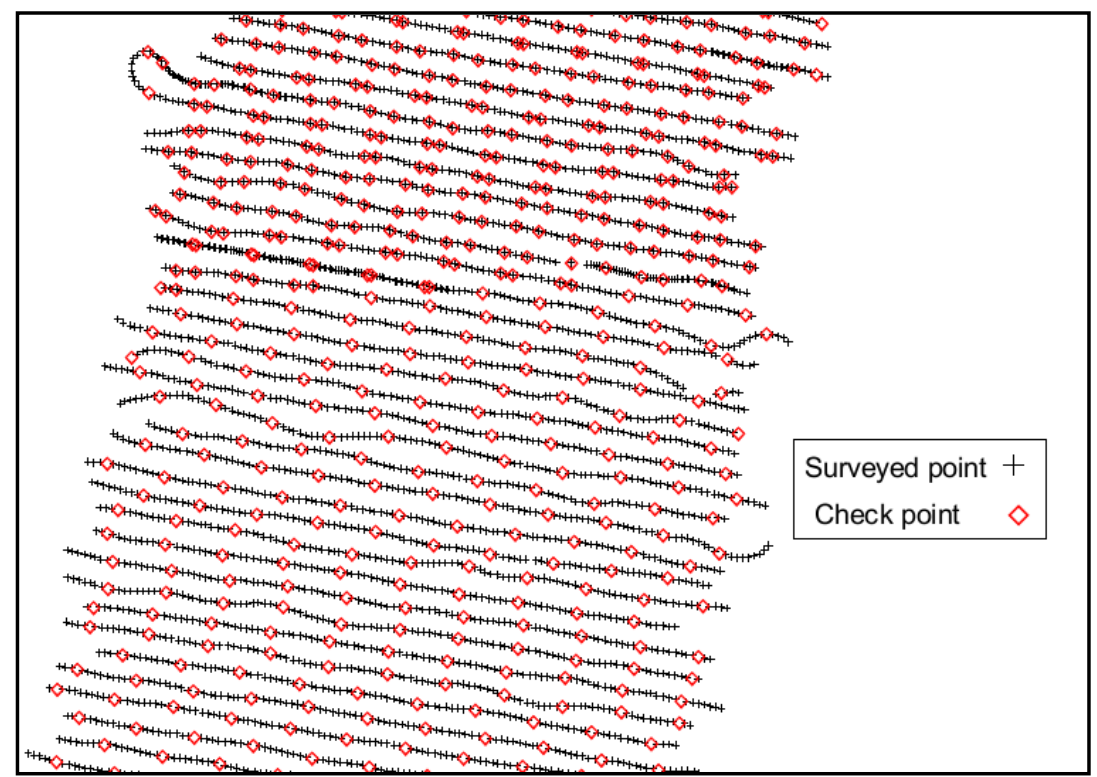

Figure (4) Samples of the surveyed and the check points.

Mean, minimum, maximum, mean absolute, root mean square errors, and other factors, are the statistical terms that are usually employed to evaluate the overall performance of the interpolation methods. The measure most widely used as a single spatial global statistic is the root mean square error (RMSE), which measures the dispersion of the frequency distribution of deviations between the original points and interpolated points. RMSE expresses the degree to which the interpolated values differ from the measured values, and is based on the assumption that errors are random with a mean of zero and normally distributed. Several studies showed that the mean error has not been found to equal zero and therefore some researchers have recommended the use of mean absolute error and standard deviation indices (Weng, 2006). The main attraction of RMSE lies in its straightforward concept and easy computation mathematically and it is expressed as:

$$
R M S E=\sqrt{\sum_{i=1}^{N}\left(\left(Z_{i}(x, y)-\widehat{Z}_{i}(x, y)\right)^{2} / N\right.}
$$

where; $Z_{i}(x, y)$ is the predicted value at coordinates $\mathrm{x}, \mathrm{y}$ and $\widehat{Z}_{i}(x, y)$ is the observed value at the same coordinates, and $N$ is the number of tested points.

In the present work, the data analysis was carried out using MATLAB® software, at which, its interpolation function "griddata" was replaced with script "surfergriddata". This script utilizes the interpolation functions of Surfer Golden Software in creation DTM grids (Grinsted 2006). Table (1) shows the values of mean absolute and RMSE of the difference between the measured levels of the three check lines and the corresponding interpolated levels. The different DTM gridding techniques have been investigated with three grid sizes, namely, 50, 30, and 10 meters. It is obvious that the results are almost similar expect in MSP, PRG, MAV, and DMT techniques. These techniques are excluded in the further investigation where RMSE and mean absolute 
of these techniques are too high and not acceptable for modelling the bathymetric survey data, specially MSP and DMT techniques.

Table (1) Results of the first validation for all Gridding techniques

\begin{tabular}{|c|c|c|c|c|c|c|}
\hline \multirow[b]{2}{*}{$\begin{array}{l}\text { Interp. } \\
\text { Tech. }\end{array}$} & \multicolumn{2}{|c|}{ Grid $50 \mathrm{~m}$} & \multicolumn{2}{|c|}{ Grid $30 \mathrm{~m}$} & \multicolumn{2}{|c|}{ Grid $10 \mathrm{~m}$} \\
\hline & $\begin{array}{c}\text { Mean } \\
\text { Abs. (m) }\end{array}$ & $\begin{array}{c}\text { RMSE } \\
(\mathrm{m}) \\
\end{array}$ & $\begin{array}{c}\text { Mean } \\
\text { Abs. (m) }\end{array}$ & $\begin{array}{c}\text { RMSE } \\
(\mathrm{m})\end{array}$ & $\begin{array}{c}\text { Mean } \\
\text { Abs. }(\mathrm{m})\end{array}$ & $\begin{array}{l}\text { RMSE } \\
(\mathrm{m})\end{array}$ \\
\hline IDP & 0.16 & 0.19 & 0.12 & 0.15 & 0.11 & 0.14 \\
\hline KRG & 0.13 & 0.16 & 0.10 & 0.12 & 0.09 & 0.11 \\
\hline MCV & 0.16 & 0.19 & 0.11 & 0.13 & 0.09 & 0.11 \\
\hline MSP & 22.21 & 70.25 & 9.15 & 35.23 & 16.33 & 73.90 \\
\hline NTN & 0.13 & 0.16 & 0.10 & 0.12 & 0.09 & 0.11 \\
\hline NEN & 0.14 & 0.17 & 0.10 & 0.13 & 0.10 & 0.12 \\
\hline PRG & 2.20 & 2.53 & 2.17 & 2.51 & 2.18 & 2.52 \\
\hline RPF & 0.14 & 0.17 & 0.10 & 0.13 & 0.10 & 0.12 \\
\hline TIN & 0.13 & 0.16 & 0.10 & 0.12 & 0.09 & 0.11 \\
\hline MAV & 2.19 & 2.24 & 2.17 & 2.21 & 2.17 & 2.21 \\
\hline DMT & 44.96 & 44.96 & 44.96 & 44.96 & 44.96 & 44.96 \\
\hline $\mathrm{LPL}$ & 0.20 & 0.24 & 0.17 & 0.20 & 0.15 & 0.18 \\
\hline
\end{tabular}

The remained eight DTM interpolation techniques have been evaluated by the splitsample method where $10 \%$ of the bathymetric data was omitted to be used as check points.
These check points are distributed over the bed and the side slops areas rather than the three longitudinal check lines which cover the bed area only as shown in Figure (4).

Table (2) Results of the second evaluation for eight gridding techniques

\begin{tabular}{|c|c|c|c|c|c|c|c|c|c|c|c|c|}
\hline \multirow{2}{*}{$\begin{array}{c}\text { Interp. } \\
\text { method }\end{array}$} & \multicolumn{4}{|c|}{ Spacing 50 } & \multicolumn{4}{c|}{ Spacing 30 } & \multicolumn{4}{c|}{ Spacing 10 } \\
\cline { 2 - 13 } & $\begin{array}{c}\text { Min } \\
(\mathrm{m})\end{array}$ & $\begin{array}{c}\text { Max } \\
(\mathrm{m})\end{array}$ & $\begin{array}{c}\text { Mean } \\
\text { Abs } \\
(\mathrm{m})\end{array}$ & $\begin{array}{c}\text { RMSE } \\
(\mathrm{m})\end{array}$ & $\begin{array}{c}\text { Min } \\
(\mathrm{m})\end{array}$ & $\begin{array}{c}\text { Max } \\
(\mathrm{m})\end{array}$ & $\begin{array}{c}\text { Mean } \\
\text { Abs } \\
(\mathrm{m})\end{array}$ & $\begin{array}{c}\text { RMSE } \\
(\mathrm{m})\end{array}$ & $\begin{array}{c}\text { Min } \\
(\mathrm{m})\end{array}$ & $\begin{array}{c}\text { Max } \\
(\mathrm{m})\end{array}$ & $\begin{array}{c}\text { Mean } \\
\text { Abs } \\
(\mathrm{m})\end{array}$ & $\begin{array}{c}\text { RMSE } \\
(\mathrm{m})\end{array}$ \\
\hline IDP & -1.64 & 1.60 & 0.22 & 0.33 & -1.43 & 1.16 & 0.17 & 0.27 & -1.27 & 1.15 & 0.11 & 0.19 \\
\hline KRG & -1.64 & 1.60 & 0.21 & 0.33 & -1.34 & 1.12 & 0.14 & 0.24 & -1.18 & 1.40 & 0.11 & 0.19 \\
\hline MCV & -1.61 & 1.70 & 0.22 & 0.33 & -1.50 & 1.51 & 0.16 & 0.25 & -1.19 & 1.39 & 0.10 & 0.17 \\
\hline NTN & -1.58 & 1.56 & 0.19 & 0.30 & -1.39 & 1.12 & 0.15 & 0.24 & -1.19 & 1.36 & 0.10 & 0.16 \\
\hline NEN & -1.69 & 1.80 & 0.21 & 0.33 & -1.55 & 1.27 & 0.16 & 0.26 & -1.43 & 1.56 & 0.10 & 0.17 \\
\hline RBF & -1.65 & 1.55 & 0.20 & 0.31 & -1.38 & 1.20 & 0.15 & 0.24 & -1.18 & 1.40 & 0.11 & 0.19 \\
\hline TIN & -1.55 & 1.46 & 0.19 & 0.31 & -1.45 & 1.16 & 0.15 & 0.24 & -1.17 & 1.40 & 0.09 & 0.16 \\
\hline LPL & -2.05 & 1.88 & 0.30 & 0.55 & -1.98 & 1.80 & 0.27 & 0.40 & -1.78 & 1.74 & 0.24 & 0.37 \\
\hline
\end{tabular}

The results in Table (2) show the minimum and maximum values of the differences between the measured and the estimated levels of the check points with three grid sizes of 50 , 30 , and 10 meters. The mean absolute and RMSE of these differences are also calculated and used as the main evaluation factors. The bar chart in Figure (5) illustrates the RMSE in the three cases of the grid size. As observed from both, the table and the chart, it is clear that decreasing the grid size improves the performance of the gridding techniques. The worst results were obtained from LPL technique for the different grid sizes. The other techniques have almost similar performance however TIN and NTN techniques give relatively the accurate results. 


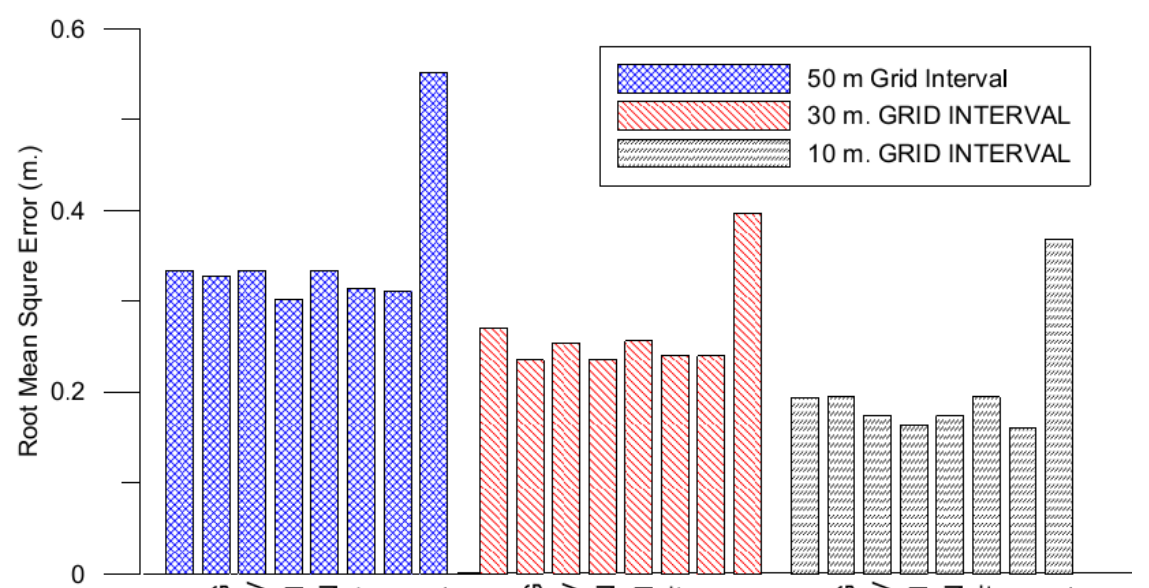

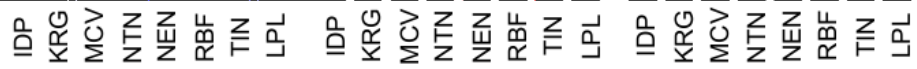

Figure (5) RMSE of eight gridding techniques

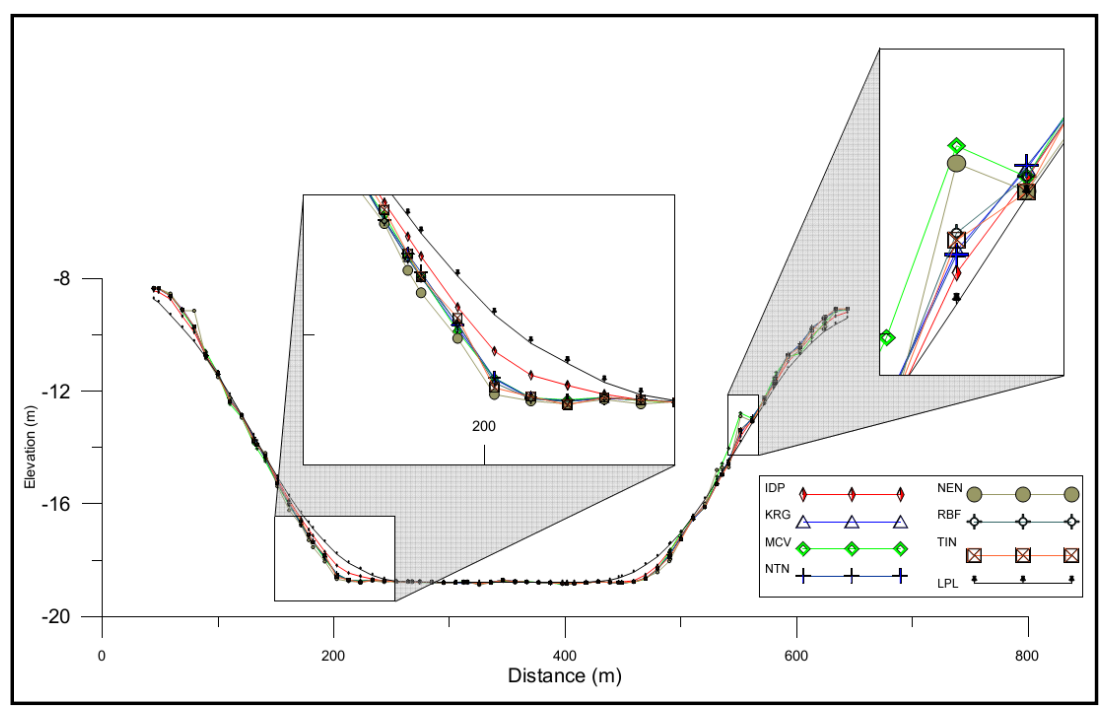

Figure (6) Interpolated cross section using different DTM gridding techniques.

To compare the effect of DTM interpolation techniques on the resulted cross sections, the interpolated levels of a sample cross section are plotted in Figure (6). The different techniques give almost the same levels at the navigation channel bed and the changes starts near the two channel toes and continue at the side slops.

Some applications require continuous updating of DTM of the seafloor in real time such as dredging monitoring and control. In this case, fast DTM gridding techniques are essential to minimize the time lag between the depth measurements and updating the DTM. To investigate the performance of the gridding techniques in real time, the times required for creating DTM using each technique with different grid sizes of 50,30,10,5 m have been measured and listed in Table (3). It is obvious that the grid spacing has great impact on the DTM time creation. Considering the minimum grid spacing, TIN technique is considered the fastest DTM gridding technique. It is also the fastest in case of grid spacing 10 and $30 \mathrm{~m}$, while NEN technique is the fastest in case of the $50 \mathrm{~m}$ grid spacing. RBF technique is the slowest technique followed by KRG technique. 
Table (3) Time in seconds for creating DTM using gridding techniques

\begin{tabular}{|c|c|c|c|c|}
\hline Interp.tech. & $\begin{array}{c}\text { Spacing 50 } \\
\mathrm{m}\end{array}$ & $\begin{array}{c}\text { Spacing 30 } \\
\mathrm{m}\end{array}$ & $\begin{array}{c}\text { Spacing 10 } \\
\mathrm{m}\end{array}$ & $\begin{array}{c}\text { Spacing 5 } \\
\mathrm{m}\end{array}$ \\
\hline IDP & 0.20 & 0.49 & 7.15 & 26.2 \\
\hline KRG & 0.96 & 4.98 & 35.20 & 126.1 \\
\hline MCV & 0.07 & 0.19 & 3.23 & 16.3 \\
\hline NTN & 0.15 & 0.25 & 2.98 & 5.21 \\
\hline NEN & 0.04 & 0.13 & 2.61 & 5.4 \\
\hline RBF & 13.10 & 34.00 & 311.20 & 1142 \\
\hline TIN & 0.08 & 0.09 & 0.30 & 0.35 \\
\hline LPL & 0.23 & 0.85 & 9.99 & 35.5 \\
\hline
\end{tabular}

\section{4- CONCLUSIONS}

In the current study, different DTM interpolation techniques have been used to model the bathymetric survey of PSEP maintenance dredging project. The techniques have been evaluated by independent set of sample data and split-sample methods. Based on the results of the study, there is no certainly best interpolation technique but only the optimal choice for the considered bathymetric data. Therefore, since TIN and NTN techniques have the least RMSE with the different grid sizes and reached $0.16 \mathrm{~m}$ at $10 \mathrm{~m}$ grid size, they are considered the accurate techniques. The results also showed that the grid size of DTM has an influence on the performance of the interpolation technique where decreasing the grid size decreases the values of the used statistical terms and this indicates the improving of the precision. The grid size also has great impact on the time of DTM creation where the time is a key factor in real time DTM applications. The results showed that the TIN technique is the fastest interpolation techniques where its time reached 0.35 second for creating DTM with $5 \mathrm{~m}$ grid size while the next best time is 5.21 seconds by NTN technique. Therefore, TIN technique can be considered the most suitable interpolation for real time applications.

\section{REFERENCES}

[1] Bobach, T., Umlauf, G., 2007. Natural neighbor concepts in scattered data interpolation and discrete function approximation. Proceeding of Visualization of Large and Unstructured Data Sets: Second workshop of the DFG's International Research Training Group, September 911, 2007 Kaiserslautern, Germany.
[2] Buhmann, M. D., 2003. Radial Basis Functions: Theory and Imple mentations, Cambridge University Pres s, ISBN 978-0-521-63338-3.

[3] Canadian Hydrographic Service (CHS), 2005. CHS Standards for Hydrographic Surveys, First Edition, Fisheries and Oceans Canada.

[4] Eberly, S., Swall, J., Holland, D., Cox, B., Baldridge, E., 2004. Developing Spatially Interpolated Surfaces and Estimating Uncertainty., U.S. Environmental Protection Agency, Research Triangle Park, NC 27711, Report No. EPA-454/R-04-004, 1-160.

[5] El-Sheimy, N., Valeo, C., Habib, A., Valeo, C., 2005. Digital Terrain Modeling: Acquisition, Manipulation And Applications., Artech House, United Kingdom.

[6] Erdogan, S, 2009. A comparision of interpolation methods for producing digital elevation models at the field scale, Earth Surf., Processes and Landforms Vol. 34(3),366-376.

[7] Federation Iinternationale des Geometres FIG., 2010. Guidelines for the Planning, Execution and Management of Hydrographic Surveys in Ports and Harbours 2010., International Federation of Surveyors, FIG Commission 4 No 56.

[8] Grinsted, A ., 2006. Surfer Griddata, Matlab central website, The MathWorks Inc., retrieved 1/11/2013 ,http://www.mathworks.com/matlabcent ral/filee xchange/10986-surfer-griddata.

[9] International Hydrographic Organization (IHO), 2008. IHO Standards for Hydrographic Surveys. 5th edition, International Hydrographic Bureau, Monaco, Special Publication No: 44. 
[10] Kay, M., Dimitrakopou-los , R., 2000. Integrated Interpolation Methods for Geophysical Data: Applications to Mineral Exploration., Natural Resources Research, Vol. 9(1), 53-64.

[11] Kearns, T.A., Breman, J., 2010. Bathymetry: the art and science of seafloor modeling for modern applications., Breman, J. (Ed.) ,2010. Ocean globe.,1-36, Breman, J. (Ed.), 2010. Ocean globe. ESRI Press: Redlands. ISBN 978-1-58948-219-7. 274.

[12] Kravchenko, A.N., Bullock, D.G., 1999. A comparative study of interpolation methods for mapping soil properties., Journal of Agronomy 91, 393- 400.

[13] Lam, N., S.N., 1983. Spatial Interpolation Methods: A Review., The American Cartographer, Vol. 10(2), 129-149.

[14] Li, Z., Zhu, Q., Gold, C., 2005. Digital Terrain Modeling: Principles and Methodology., CRC Press: Boca Raton, FL, 323 pp.

[15] Rawlings, J.O., Pantula, S.G., Dickey, D. A., 1998. Applied Regression Analysis: A Research Tool., Springer, New York.

[16] Sibson, R., 1981. A brief description of nearest neighbor interpolation interpolating multivariate Data., John Wiley \& Sons, New York, 21-36.

[17] Thacker, W.I., Zhang, J., Watson, L.T., Birch, J.B., Iyer. M.A., Berry M.W., (2010), Algorithm XXX: SHEPPACK: Modified Shepard Algorithm for Interpolation of Scattered Multivariate Data., ACM Trans. Math. Software, 37, Article 34,1-20.

[18] Tomczak, M., 1998. Spatial Interpolation and its Uncertainty Using Automated Anisotropic Inverse Distance Weighting (IDW) - Cross Validation/Jackknife Approach., Journal of Geographic Information and Decision Analysis, vol.2, 18-33.

[19] Weng, Q., 2006. An evaluation of spatial interpolation accuracy of elevation data., In Progress in Spatial Data Handling, Riedl A, Kainz W, Elmes GA (eds). Springer-Verlag: Berlin; 805- 824.

[20] Yanalak, M., 2003. Effect on gridding method on digital terrain model profile data based on scattered data., Journal of Computing in Civil Engineering, Vol. 17(1), 58-67.

[21] Yang, C.S., Kao, S.P., Lee, F.B., Hung, P. S., 2004. Twelve different interpolation methods: A case study of Surfer 8.0., Proceedings of the XXth ISPRS Congress, 35. 